\title{
Palliative Patients' and Relatives' Views on Using Telemedicine in Palliative Care - A Pilot Study from Southern Denmark
}

\author{
Kirsten Bachmann ${ }^{1,2}$, Georg Bollig ${ }^{1,2^{*}}$, Anette Brink ${ }^{3}$ \\ ${ }^{1}$ Palliative Care Team, Medical Department Sфnderborg/Tønder, South Jutland Hospital, Denmark \\ ${ }^{2}$ Palliative Care Research Group, Medical Research Unit, Institute of Regional Health Research, University of \\ Southern Denmark

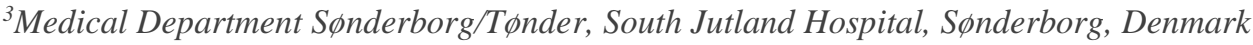

*Corresponding Author: Georg Bollig, Palliative Care Team, Medical Department Sønderborg/ Tфnder, South Jutland Hospital, Denmark. Email: georg.bollig@ rsyd.dk

\begin{abstract}
Background: Many people want to die at home. Telemedicine could probably provide better access to specialised palliative care especially in rural areas.

Method: A qualitative study with interviews of patients and relatives. The informants were asked for their opinion about telemedicine and their interest in participation in consultations via telemedicine. 15 palliative patients ( 7 women and 8 men aged 29 - 80 years) and 5 relatives were included.

Results: Most participants from our study are positive about using telemedicine in palliative care. Besides the more personal contact, another advantage might be that relatives and other health carers may also participate in video-consultations. Most men stated that it would be easier to show bodily changes and that the contact could be more personal. Many women prefer consultations by phone. Many informants state that telemedicine could not replace a face-to-face meeting, but would be superior compared to a phone call.

Conclusion: Our pilot study suggests that the overall idea of using telemedicine in palliative care is acceptable for almost all patients and relatives. Nevertheless, many women from our pilot study would prefer a telephone consultation without a camera. Future research should aim to investigate patients' and relatives' experiences with telemedicine in palliative care.
\end{abstract}

Keywords: Telemedicine, remote consultation, video consultation, telehealth, e-health, palliative care, specialized palliative care, rural, home death.

Abbreviations: SPCT = Specialised Palliative Care Team , GP = General practitioner, BYOD = Bring-your own-device

\section{INTRODUCTION}

Within the last years medical treatment of cancer and other life-limiting diseases has improved and life expectancy has increased in general. At the same time the number of patients who suffer from chronic diseases, multi-morbidity and dementia has increased [1-3]. In European countries most people prefer a home death rather than dying in an institution such as a nursing home or a hospital $[4,5]$. Furthermore, many people with life-limiting diseases want to stay at home for as long as possible. An organized cooperation between general practitioners (GP), nurses and the patients' relatives seems, therefore, to be an essential factor in increasing the likelihood of home death. Besides shortness of breath and nausea, one of the most important barriers for death at home is the lack of relatives who are involved in care for the dying person [6]. The demographic change is a major challenge for rural areas in terms of resource availability.

The use of modern technology such as telemedicine, including videoconferences, can provide healthcare at a distance, and specialist palliative care services when needed. As many general practitioners in rural areas may have insufficient knowledge to manage the complex problems of palliative care patients, telemedicine can help to reinforce and enhance advice and help for patients, relatives and general practitioners (GPs). Patient problems may include physical, social, psychological and spiritual dimensions, which have been described as total pain by Cicely Saunders [7]. Members of Danish specialised palliative care teams (SPCTs) state that videoconferences have an "added 
communicative value" but that they do not replace face-to-face communication and home visits entirely [8]. Recent reviews have indicated that telemedicine can be useful within palliative care. Most users are positive about the use of technology in palliative care $[9,10]$.

Telemedicine might provide a feeling of security and contribute to building trust between patients, relatives and healthcare providers $[9,10]$. The provision of specialized palliative care at home is both desired and needed and may contribute to avoiding unwanted hospitalization at the end of life. Telemedicine might have the potential to increase the possibility of home death $[9,10]$.

The following definitions for palliative care and telemedicine used in this study have been defined by the World Health organization (WHO).

Palliative care [11]:

"An approach that improves the quality of life of patients and their families facing the problem associated with life-threatening illness, through the prevention and relief of suffering by means of early identification and impeccable assessment and treatment of pain and other problems, physical, psychosocial and spiritual."

Telemedicine [12]:

"The delivery of health care services, where distance is a critical factor, by all health care professionals using information and communication technologies for the exchange of valid information for diagnosis, treatment and prevention of disease and injuries, research and evaluation, and for the continuing education of health care providers, all in the interests of advancing the health of individuals and their communities".

The aim of this pilot study was to explore the views of palliative patients and their relatives on the use of telemedicine and video communication within palliative care.

\section{Materials \& MethodS}

The presented pilot study was the first part of an ongoing project [13]. It was designed as a qualitative pilot-study with telephone and face-to face interviews of patients and relatives about their views on the use of telemedicine and video communication in palliative care without having any prior practical experience with it. The results of this pilot study form the baseline for an implementation study on telemedicine. For the purpose of this paper telemedicine refers specifically to video consultations carried out between patients and health care professionals.

\subsection{Setting}

The study was performed in South Jutland, a Danish region with a size of $3.939 \mathrm{~km}^{2}$ and approximately 250.000 inhabitants. It is a rural area with 46 inhabitants per square kilometre [14]. The region is served by the SPCT of the South Jutland Hospital [15]. Visiting a patient at home may, in some cases, include a two-hour drive plus time for the consultation in the patient's home (usually at least an hour) and additional paperwork, thus resulting in a timeneed of up to four hours for the first visit of a single patient.

\subsection{Participating Patients and Relatives}

Inclusion criteria for palliative patients were:

- suffering from a life-limiting cancer disease with complex palliative care needs

- referred to the specialized palliative care team

All included patients were suffering from advanced cancer and had been ill for 1 to 16 years prior to inclusion in the study. They were all assigned to the specialized palliative care team and were accustomed to having regular followup contact with the team through follow-up phone calls. The participants lived in an area of within 3 - 60 kilometres from the hospital where the SPCT is based. In addition, relatives of patients assigned to the SPCT were included as informants. Inclusion criteria for relatives were status as the relative of a cancer patient assigned to the SPCT. Table 1 and 2 show demographic data of the palliative patients including cancer diagnosis. Table 3 illustrates relatives' connections to the patients.

Table1. Participating palliative patients - gender and age range

\begin{tabular}{|c|c|c|}
\hline Gender & Number of patients & Age range \\
\hline Male & 8 & $42-71$ \\
\hline Female & 7 & $29-80$ \\
\hline
\end{tabular}

Table2. Cancer diagnoses of participating patients $(n=15)$

\begin{tabular}{|l|c|}
\hline Type of cancer & number \\
\hline Breast cancer & 3 \\
\hline Ovarian cancer & 1 \\
\hline Prostate cancer & 2 \\
\hline Kidney cancer & 1 \\
\hline Lung cancer & 4 \\
\hline Pancreatic cancer & 2 \\
\hline Myelomatosis & 1 \\
\hline Liver cancer & 1 \\
\hline
\end{tabular}


Table3. Relatives - gender and relation to the patients

\begin{tabular}{|l|c|}
\hline Relatives $(\mathbf{n}=\mathbf{5})$ & number \\
\hline Male & 1 \\
\hline Female & 4 \\
\hline Spouse & 3 \\
\hline Daughter & 2 \\
\hline
\end{tabular}

\subsection{Data Collection}

Interviews took place via telephone or face-toface. Data were collected within a 6-month period from November 2017 to April 2018. The content of the interviews and informants' citations were documented as notes by the interviewing palliative care nurse. The interviews were conducted by two different nurses who had the main contact with the patient to ensure personal contact and trust. Contact nurses gathered data by asking the patients and relatives a few questions on the phone or in face-to-face meetings. All informants were recruited via telephone except one relative who was asked to participate in the study during the first home visit of the SPCT. All informants received information about the purpose of the study and gave informed consent to participate. The interview guide used is described below:

\subsection{Interview Guide for Telephone Interviews of Patients and Relatives}

1. Do you have a personal computer with a camera and a microphone or a tablet with internet-connection in your home?

2. Would you like to participate in video communication with a doctor and nurse instead of speaking to them via telephone?

3. Do you think video communication could be more advantageous than using a telephone for communication?

4. Would you like to participate in video communication with the palliative care team and others (for example with your primary care nurses, your general practitioner, relatives who live far away or others involved)?

5. Do you have any other comments?

The answers and the content of the interview were documented by writing notes during the interview as accurately as possible. A summary of the results was given to the informants at the end of the interview in order to obtain an immediate validation on the statements given. This gave the informants the opportunity to correct their answers or to agree that the summary was reflective of their views and opinions.

\subsection{Analysis}

Qualitative data were analysed using qualitative description [16-18]. The following steps guided the analysis process of the qualitative interview data:

1. All authors read the interview notes and familiarized themselves with the data

2. KHB and GB identified preliminary codes and themes

3. All authors compared and discussed the preliminary codes and themes

4. All authors discussed the revised codes and themes and agreed on the final codes and themes

5. All authors checked the interview notes in order to question the findings

6. All authors discussed the findings and themes and agreed about the interpretation of the data

Data reporting of the qualitative data was guided by the COREQ guidelines [19].

\subsection{Ethical Considerations}

All participants were informed about the study and were given the opportunity to ask clarifying questions before participating. They were informed about the possibility of withdrawing from the study at any time. All informants gave their informed consent to participate. The study has been reported to the regional Danish ethics committee (S-20172000-119) and the Danish Data Protection Agency (2008-58-0035).

\section{RESUltS}

The main findings of the study show that many informants would value using telemedicine for follow-up consultations in palliative care. Most of them find it probable that the ability to see each other could ease communication. Table 4 provides an overview of the answers to the standardized opening questions. One of the palliative patients did not have a computer himself, but said that his wife had one. Another stated that telephone contact was sufficient for him and that he, therefore, did not see the need for video consultations with the SPCT. 
Table4. Palliative patients $(n=15)$ answers to the opening questions

\begin{tabular}{|l|l|l|}
\hline Question & Male $(\mathbf{n}=7)$ & Female $(\mathbf{n}=\mathbf{8})$ \\
\hline $\begin{array}{l}\text { 1. Do you have a personal computer with camera/microphone or a } \\
\text { tablet with internet-connection in your home? }\end{array}$ & $\begin{array}{l}\text { Yes: } 6 \\
\text { No: } 1\end{array}$ & $\begin{array}{l}\text { Yes: } 7 \\
\text { No: } 1\end{array}$ \\
\hline $\begin{array}{l}\text { 2. Would you like to participate in video communication with a } \\
\text { doctor and nurse instead of speaking to them via telephone? }\end{array}$ & $\begin{array}{l}\text { Yes: } 3 \\
\text { No: } 3 \\
\text { Don't know: } 1\end{array}$ & Yes: 7 \\
\hline $\begin{array}{l}\text { 3. Do you think video communication could be advantageous than } 1 \\
\text { using a telephone for communication? }\end{array}$ & $\begin{array}{l}\text { Yes: } 3 \\
\text { No: } 4\end{array}$ & Yes: 5 \\
\hline $\begin{array}{l}\text { 4. Would you like to participate in video communication with the } \\
\text { palliative care team and others (for example with your primary care }\end{array}$ & $\begin{array}{l}\text { Yes: } 2 \\
\text { No: } 4 \\
\text { nurses, your general practitioner, relatives who live far away or } \\
\text { others involved)? }\end{array}$ & Don't know: 1 \\
\hline
\end{tabular}

\section{Themes from the Interviews of Palliative Patients and Relatives}

There were four main themes in the interviews. These include: technical equipment at home, appearance, vision and the patients' physical and mental condition; practical and organizational matters and barriers to using telemedicine. Each theme is presented under a subheading.

\section{Technical Equipment at Home - "Everyone has} a Computer"

Almost all participants have a computer or tablet device at home and would therefore be able to participate. Two stated that they didn't have sufficient internet connection, but said if the internet connection was better they would like to participate in video consultations with the SPCT. One informant would rely on the help from his wife.

"I am not so good at using a tablet; normally my wife helps me."

This shows that it is possible for participants to use their own equipment. Therefore, a bringyour-own-device (BYOD) approach is applicable. Many informants value the opportunity of video consultations as a means of communication.

Appearance, Vision and the Patients Physical and Mental Condition - "To Be Seen or Not To Be Seen"

The data from our study indicates a probable gender difference. Some of the female patients did not want to participate in telemedicine as a means of communication because of concerns about how they appear on screen. They were concerned that their eyesight was too bad or they were too weak to communicate at all.

"I have bad eyesight and I need to concentrate too much... and then I get tired."

Some women did not want to be dependent on a time schedule. In contrast, most men stated that they would participate in telemedicine. Many men found it easier to explain their needs or even show where pain might be located or to ask questions which could be supported by showing physical changes.

"I could ask if the spot on the skin is cancer and would be able to show it to the doctor and the nurse".

Some male informants expect that they might receive quicker answers from the health care personnel. Telemedicine might also help to control their medication (by showing their tablets), and to make sure that everybody is talking about the same thing.

Some informants state that it could improve communication and strengthen the relationship with the palliative care team.

"You can see each other. Its closer to a physical meeting...You can also see the mimic."

Only one patient thought he would not be capable of taking part in video consultations due to his poor physical condition. Many relatives thought that telemedicine could be useful for some patients. Some relatives voiced their concerns about the cognitive conditions of the patients and questioned if the patients would be capable of participating in video consultations. Relatives also describe an advantage in the ability to see one another; both in relation to physical and mental conditions.

"...one can see - what is the other person thinking when they are quiet and then ask about it."

Practical and Organizational Matters "Communication Needs and Preferences are Different"

Some informants, who would like to participate in telemedicine, claimed it could probably be better than phone calls alone, but could not replace the face-to-face visit. 
One woman mentioned that it would not be practical to have a video consultation with the SPCT because her husband would have to sit in front of the computer instead of walking around while talking on the phone.

"He normally walks around in the house or garden, when he talks to you (the SPCT)"

Some informants meant that they would get the same sufficient support, when they use the phone and saw no additional benefit in using telemedicine. Another imagined that telemedicine could be a good option for young people who are used to navigating on Skype and other social media.

The group differed in opinion concerning the possibility of including others, other than the patient and the SPCT, for example the patients GP or relatives living far away. Many informants did not see a need for including others in the video consultations with the SPCT. Some informants would prefer one or two participants. Most of those who thought that participation of others would be a good idea, said they would appreciate it, when relatives living fare away could participate.

Most patients would like their next-of-kin to participate, as they often help with medication and other things.

"If it is my wife (who shall participate in video consultations) it is okay, because she manages my tablets."

One patient voiced concerns that it may be difficult to receive bad news via a video consultation without the physical presence of the doctor.

"So I'm sitting all alone after the doctor gave me bad news about my prognosis."

This finding indicates that it is important to differentiate between which topics can be discussed in video consultations and which can't. Breaking bad news seems to need a face-to-face meeting.

\section{Barriers for Using Telemedicine - "Lacking Knowledge about Possible Benefits"}

Some of the informants had difficulty imagining what telemedicine is or how a video consultation with the SPCT would take place. Even though the interviewer gave a short description of telemedicine many informants without prior experience of video consultations via Skype, Facetime or other modern means of communication had difficulty understanding the purpose of video consultations. One patient was married to a foreign woman and wondered if it could be hard for her to understand what telemedicine was all about. Some informants were doubtful about telemedicine, as the telemedicine in our study proposed to include scheduled video consultations, --. Some said that they didn't want to be bound to a time schedule, and would prefer a none-scheduled phone call instead. Technical problems as a barrier for telemedicine were seldom mentioned. Most people do have a computer and internet connection. However, some informants from rural regions stated that their internet-connection was insufficient.

\section{DisCUSSION}

The results of this pilot-study show that many patients and relatives value the potential use of telemedicine in palliative care provision. Almost all informants had a computer and internet access at home. This shows that a "bring your own device" (BYOD) approach is feasible in the rural area of Southern Denmark, as planned for our ongoing project [13]. This situation might be similar to most European and Western countries. Our findings indicate that telemedicine could be an alternative to phone calls but would not be able to replace all face-to-face meetings. All the participants had the first contact with the SPCT face-to-face. This is in accordance with other studies that assume, that the first contact has to be face-to-face to ensure the trust of the patients and their relatives and obtain informed consent for using telemedicine $[8,20]$. This is in line with standard practical and ethical conduct in palliative care and the need for an initial assessment of the patient and his needs including a physical examination. Nevertheless, telemedicine could serve as a routine follow-up measure saving resources and enabling an SPCT to have more follow-up conversations using video consultation as opposed to home visits due to a reduction in travel time. In rural regions specialized palliative care teams (SPCTs) often cover large areas incurring long drives when visiting patients in their own homes. Due to these geographical challenges and limited resources, home visits by SPCTs are restricted. In order to meet the increasing number of patients who will need specialized palliative care at home, telemedicine and telehealth options have been suggested as measures to ease these problems $[21,22]$. A Danish study found healthcare professionals" concerns about being "seen" on a 
camera that can pose a challenge because they were worried about appearance [8]. That matches one of the female patients in this study. Concerns about appearance should, therefore, be addressed before starting video consultations and patients' preferences for communication (telephone versus telemedicine) should be respected.

The results' of the presented interviews shows that the cognitive condition is important to the patients and the relatives; whether the patients can use the modern technology or not. Therefore, healthcare personnel should consider, timing when introducing telemedicine, how advanced the patients' condition is and when to conclude use of telemedicine. The situations in which video consultations can replace physical meetings should be explored through further research [9]. The results from our interviews inform us about the habits some patients have while they talk with the SPCT on the phone (such as walking around). This is in line with the findings from the healthcare professionals who stated there would be more focus on the communication, when they were using telemedicine compared to a telephone [8]. Not all informants think, that several participants in a video conference is convenient. Some say it may create a disturbance. Findings from Scotland have shown that both patients and carers appreciate telehealth as an addition to clinical care [21]. Telemedicine is applicable and feasible in a Danish context $[9,10,20]$. Current reviews from Denmark conclude that telemedicine is useful in palliative care for communication between the SPCT and patients and relatives and that telemedicine is useful in teaching district nurses $[9,10]$.

\section{CONCLUSION}

In conclusion, many informants see telemedicine as a meaningful addition and communication tool in palliative care. According to their views telemedicine, including video consultations might be superior to follow-up telephone calls. Even though many informants would like to use telemedicine in the follow-up, others would prefer follow-up by telephone. Nevertheless, many informants do appreciate physical home visits when possible. Telemedicine might be a good tool for communication and follow-up especially in rural areas where home visits are restricted by geographical distances and lack of resources. Further research on the use of telemedicine in palliative care is needed. This applies especially to the question of when to introduce and when to conclude the use of telemedicine including situations where telemedicine could be preferable.

\section{LIMITATIONS}

One could argue that our pilot-study used telephone interviews and that some participants might not have a proper understanding of the difference between a follow-up call by telephone or a telemedicine consultation. However, taking into account the widespread use of video communication using internet platforms, one may also argue that many people do have practical experience with the use of such techniques. Nevertheless, some informants' answers indicate that some participants probably do not fully understand what video consultations entail. Therefore, it may be difficult to make definite conclusions based on our data material. On the other hand, the interviewers were nurses with experience in telephone follow-up calls with patients which could be considered as a strength. Another obvious limitation is the fact that the interviews were not recorded and consisted of notes taken by the interviewer. To reduce this bias an informant check was used at the end of the interview.

\section{ACKNOWLEDGEMENTS}

We would like to thank all patients and relatives who participated in the study and shared their thoughts on telemedicine with us. Thanks to Tina Holm Hansen for help in conducting the interviews with patients and relatives and Eithne Hayes Bauer for proofreading the manuscript.

\section{REFERENCES}

[1] Clegg A, Young J, Iliffe S, Rikkert MO, Rockwood K. Frailty in elderly people. Lancet. 2013;381: 752-762.

[2] Kolb GF, Weissbach L. Demografischer Wandel - Veränderungen in Gesellschaft und Medizin und Entwicklungstendenzen in der Geriatrie. (Demographic change: Changes in society and medicine and developmental trends in geritrics.) Urologe. A 2015;54(12):1701-1709.

[3] Ferri CP, Prince M, Brayne C, Brodaty H, Fratiglioni L, Ganguli M, Hall K, Hasegawa K, Hendrie H, Huang Y, Jorm A, Mathers C, Menezes PR, Rimmer E, Scazufca M; Alzheimer's Disease International. Global prevalence of dementia: A Delphi consensus study. Lancet. 2005;366:2112-2117.

[4] Gomes, B.; Higginson, I.J.; Calanzani, N.; Cohen, J.; Deliens, L.; Daveson, B.A.; Bechinger -English, D.; Bausewein, C.; Ferreira, P.L.; Toscani, F.; Meñaca, A.; Gysels, M.; Ceulemans, L.; Simon, S.T., Pasman, H.R.; Albers, G.; Hall, S.; Murtagh, F.E.; Haugen, 
D.F.; Downing, J.; Koffman, J.; Pettenati, F.; Finetti, S.; Antunes, B., Harding, R.; PRISMA. Preferences for place of death if faced with advanced cancer: a population survey in England, Flanders, Germany, Italy, the Netherlands, Portugal and Spain. Ann Oncol. 2012, 23(8), 2006-15.

[5] Rainsford S, MacLeod RD, Glasgow NJ. Place of death in rural palliative care: A systematic review. Palliative Medicine. 2016;30(8):745763.

[6] Kern $\mathrm{M}$ et al. Ambulante Palliativbetreuung Einflussfaktoren auf eine stationäre Einweisung am Lebensende. Z Palliativmed. 2007;8:155161.

[7] Saunders C, Baines M, Dunlop R. Living with Dying. 3rd ed. Oxford: Oxford University Press, 2003.

[8] Neergaard MA, Warfvinge JE, Jespersen TW, Olesen F, Ejskjaer N, Jensen AB. The impact of "modern telecommunication" in palliative carethe views of the professionals. Telemed J E Health. 2014;20(1):24-31.

[9] Jess M, Timm H, Dieperink K. Video consultations in palliative care: A systematic integrative review. Palliat Med. 2019 Sep;33(8): 942-958. doi: 10.1177/02692 16319854938. Epub 2019 Jun 12.

[10] Jess M, Bollig G, Dieperink KB, Timm H. Videokonsultationer in palliation. Omsorg 2019;2:27-31

[11] World Health Organization. WHO Definition of Palliative Care. http://www.who.int/cancer/ palliative/definition/en/Accessed 10 August 2019.

[12] World Health Organization. Telemedicine: opportunities and developments in Member States: report on the second global survey on eHealth 2009. http://www.who.int/goe/publications/ goe_telemedicine_2010.pdf Accessed 10 August 2019.

[13] Bollig G, Brink A, Skjøt-Arkil H, 5, Ungermann Fredskild T, Bachmann KH, Sørensen TL.The stakeholders' views on and experiences with the use of telemedicine to improve palliative care in rural areas - a study protocol for a mixed methods study. Research 2017;4:2409
[14] Befolkningens størrelse. Region Sønderjylland Schleswig. https://www.region.dk/region/dk/ regionswisen/verwaltung-infrastruktur/ infrastr uktur/bevoelkerung.php Accessed 10 August 2019.

[15] Bollig G, Schemmel KW, Bachmann K. The Palliative Care Team of Southern Jutland - A Model of Good Practice for Specialized Palliative Care in Rural Regions? Abstract 15th EAPC World Congress Madrid, May 2017

[16] Neergaard MA, Olesen F, Andersen RS, Sondergaard J. Qualitative description - the poor cousin of health research? BMC Med Res Methodol 2009; 9: 52.

[17] Sandelowski M. Whatever happened to qualitative description? Res Nurs Health 2000; 23: 334-340.

[18] Sandelowski M. What's in a name? Qualitative description revisited. Res Nurs Health 2010; 33: 77-84.

[19] Tong A, Sainsbury P, Craig J. Consolidated criteria for reporting qualitative research (COREQ): A 32-item checklist for interviews and focus groups. Int J Qual Health 2007; 19(6): 349-357.

[20] Funderskov KF, Raunkiær M, Danbjørg DB, Zwisler AD, Munk L, Jess M, Dieperink KB. Experiences With Video Consultations in Specialized Palliative Home-Care: Qualitative Study of Patient and Relative Perspectives. J Med Internet Res. 2019 Mar 21;21(3):e10208. doi: $10.2196 / 10208$.

[21] Johnston B1, Kidd L, Wengstrom Y, Kearney N. An evaluation of the use of Telehealth within palliative care settings across Scotland. Palliat Med. 2012 Mar;26(2):152-61. doi: 10.1177/ 026 9216311398698. Epub 2011 Mar 4

[22] Watanabe SM1, Fairchild A, Pituskin E, Borgersen $\mathrm{P}$, Hanson J, Fassbender K. Improving access to specialist multidisciplinary palliative care consultation for rural cancer patients by videoconferencing: report of a pilot project. Support Care Cancer. 2013 Apr; 21(4):1201-7. doi: 10.1007/s00520-012-1649-7. Epub 2012 Nov 17.

Citation: Kirsten Bachmann, Georg Bollig, Anette Brink, Palliative Patients' and Relatives' Views on Using Telemedicine in Palliative Care - A Pilot Study from Southern Denmark. ARC Journal of Nursing and Healthcare. 2019; 5(4):1-7. doi: dx.doi.org/ 10.20431/2455-4324.0504001.

Copyright: (C) 2019 Authors. This is an open-access article distributed under the terms of the Creative Commons Attribution License, which permits unrestricted use, distribution, and reproduction in any medium, provided the original author and source are credited. 